University of Nebraska - Lincoln

DigitalCommons@University of Nebraska - Lincoln

Faculty Publications, Department of Psychology

Psychology, Department of

$10-2009$

\title{
The Early Development of Gender Differences
}

Matthew H. Mclntyre

University of Central Florida, mmcintyr@mail.ucf.edu

Carolyn P. Edwards

University of Nebraska-Lincoln, cedwards1@unl.edu

Follow this and additional works at: https://digitalcommons.unl.edu/psychfacpub

Part of the Psychiatry and Psychology Commons

McIntyre, Matthew H. and Edwards, Carolyn P., "The Early Development of Gender Differences" (2009).

Faculty Publications, Department of Psychology. 402.

https://digitalcommons.unl.edu/psychfacpub/402

This Article is brought to you for free and open access by the Psychology, Department of at DigitalCommons@University of Nebraska - Lincoln. It has been accepted for inclusion in Faculty Publications, Department of Psychology by an authorized administrator of DigitalCommons@University of Nebraska - Lincoln. 
Published in Annual Review of Anthropology 38 (October 2009), pp. 83-97; doi: 10.1146/annurev-anthro-091908-164338 Copyright (C) 2009 by Annual Reviews. Used by permission. http://anthro.annualreviews.org

Published online June 17, 2009.

\title{
The Early Development of Gender Differences
}

\section{Matthew H. McIntyre ${ }^{1}$ and Carolyn Pope Edwards ${ }^{2}$}

\author{
${ }^{1}$ Department of Anthropology, \\ University of Central Florida, Orlando, Florida 32816; \\ email mmcintyr@mail.ucf.edu \\ ${ }^{2}$ Departments of Psychology and Child, Youth, and Family Studies, \\ University of Nebraska-Lincoln, Lincoln, Nebraska 68588; \\ email cedwards@unlnotes.unl.edu
}

\begin{abstract}
This article reviews findings from anthropology, psychology, and other disciplines about the role of biological factors in the development of sex differences in human behavior, including biological theories, the developmental course of sex differences, and the interaction of biological and cultural gendering processes at different ages. Current evidence suggests that major biological influences on individual differences in human gender, to the extent that they exist, operate primarily in early development, during and especially prior to puberty. Biological effects are likely to be mediated by relatively simple processes, like temperament, which are then elaborated through social interactions (as with mother and peers) into more complex gendered features of adult personality. Biological anthropologists and psychologists interested in gender should direct more attention to understanding how social processes influence the development and function of the reproductive endocrine system.
\end{abstract}

Keywords: reproductive ecology, evolutionary psychology, patriarchy, dominance, temperament 


\section{Introduction}

The purpose of this review is to summarize the current evidence about the role of biological factors in the development of human gender over the life course. Rather than accept the distinction between biological sex and cultural gender, we employ the term gender very broadly to include both sex differences themselves and the cultural and biological processes that shape them. At the risk of over-reaching, we address between-sex differences, related within-sex variation, and broader features of human social systems such as patriarchy. Our review begins with biological theory about gender and its application to the evolution of human sex differentiation, followed by a discussion of the developmental course of human sex differences and the various biological and social gendering processes. As such, we also consider research from many disciplines, including tentative consideration of sociocultural studies conducted from a humanistic perspective. One important topic that we unfortunately leave out is sexuality.

\section{Biological Theories about Human Gender}

Biological theory about gender (even if that term is not always used) refers to the existence, in sexually reproducing species, of two distinct reproductive strategies called parental investment and mating effort, which have been elaborated from Darwin's description of sexual selection. Parental investment encompasses activities that are costly to parents but directly contribute to the growth or survival of offspring (Trivers 1972). For some species, this investment consists almost entirely of the initial cytoplasm contained in the gametes, with no further support provided by parents, but mammals have a number of additional parental functions including lactation. Parental investment is, in principle, common to both sexual and asexual reproduction. However, finding a mate is only relevant to sexual reproduction. In some species, finding a mate may involve travel over long distances, displays of health or beauty, physical conflict with others who are seek- ing mates, or coercion of the potential mates themselves (Bateman 1948, Clutton-Brock \& Parker 1992, Dewsbury 1982). For reasons that are not fully understood (Kokko et al. 2006, Wade \& Shuster 2002), parental investment activities of many kinds are often, but not always, enacted by one physical form, which is also often the form with larger gametes, called female, and mating activities by another physical form, often with smaller, more motile gametes, called male.

In most mammals, virtually all parental investment is done by females and all mating effort by males, resulting in more notable sex differences than in other taxa (Clutton-Brock 1989, Orians 1969). The few exceptions are in species in which roles may be partially mixed and the sexes have less notable differences, and which more often have mating systems characterized as monogamous (Jarman 1983, Plavcan 2001). The primate order includes a relatively large number of monogamous species, often characterized by some level of male parental investment (Fuentes 1998). The characterization of patterns of human parental investment and mating effort has been the subject of debate among evolutionary anthropologists (Hawkes et al. 1991, 2001; Hill \& Kaplan 1993; Kaplan et al. 2000), partly because of the substantial variation among even hunter-gatherer societies in foraging and marriage systems (Wobst 1978).

Geary $(2002,2006)$ has suggested that evolved human psychological sex differences include $(a)$ adaptations for child care in women and interpersonal dominance striving in men, both of which should be largely primitive evolutionarily in that similar sex differences are present even in nonprimate mammals, (b) adaptations for coalitional aggression in men, which might be homologous with chimpanzees (Wrangham 1999), and (c) adaptations supporting the sexual division of labor, with particular focus on hunting. The latter two domains can be considered relatively more derived as they would have evolved later.

Feminine psychological adaptations for parental care have been linked to the psychometric construct of empathy, and re- 
duced empathy in men has been linked, in turn, to lower thresholds for aggression (Baron-Cohen 2002, Campbell 2006). Although dominance striving has been studied using a variety of techniques, it has not yet been closely linked with, or developed as, a particular psychometric construct (Burgoon et al. 1998). Weak associations with narcissism, sensation seeking, instrumental motivations, and externalizing behavior are likely, and there may be a developmental link between low empathy and dominance striving, making femininity-masculinity at least partly unidimensional (Campbell 2006, McIntyre \& Hooven 2009). Theorists have proposed that the primitive sex differences in parental care and interpersonal dominance striving should be reduced in humans owing to relatively low levels of polygyny and high levels of male parental investment (Geary 2002). Despite such a reduction, it would be surprising not to find associations of basic psychological dimensions of parental investment or male-male competition with biological factors, such as sex hormones, given the established role of these factors in nonhuman sex differences. Where interesting and surprising results might be found is in the interaction of these primitive biological factors with social forces. How do the evolved processes related to biological gender operate in different cultural and economic conditions?

Human sex differences in coalitional aggression and the division of labor are of particular interest to anthropologists because of their relatively recent evolution and probable role in the origins of patriarchy (Smuts 1995). It is difficult to predict how such biological systems might operate given the relative uniqueness, among all animals, of coalitional aggression and hunting as sex dimorphic features. The psychological construct that has been most commonly proposed as reflecting adaptations for coalitional aggression is called social dominance orientation, defined as "the extent to which one desires that one's in-group dominate and be superior to out-groups" (Pratto et al. 1994, p. 742), which shows substantial sex differences. Although many physical sex dif- ferences may be related to hunting ability, the psychological dimensions investigators have proposed to support sex differences in hunting and gathering in the literature are mostly cognitive, e.g., spatial rotation and object memory, rather than related to emotions or personality, in keeping with an emphasis on cognitive changes in human evolution (Kaplan et al. 2000).

The role of the reproductive endocrine system in human sex differences has been assessed using several techniques. For concurrent effects in children and adults, concentrations of sex hormones can be measured in the blood or saliva. For prenatal effects, several indirect techniques have been used, including comparison of children with congenital adrenal hyperplasia with controls, concentrations of sex hormones in amniotic fluid, and the relative lengths of the index and ring fingers, abbreviated as 2D:4D (Cohen-Bendahan et al. 2005, McIntyre 2006).

\section{Some Evidence from Adult Men and Women}

Some evidence indicates at least a small role of the reproductive endocrine system (especially androgens, like testosterone) in the ongoing maintenance of adult sex differences in empathy and dominance striving. For example, Deady et al. (2006) found a negative association of basal testosterone concentrations with maternal ambitions in women, and Hermans et al. (2006b) found evidence that an exogenous dose of testosterone reduces empathy as assessed by unconscious facial mimicry. However, levels of testosterone in women vary over the course of the menstrual cycle and even over the course of several days (Sellers et al. 2007). A number of studies have found associations between basal or exogenous levels of testosterone and behaviors or attitudes associated with dominance striving in men and women (Dabbs 1997, Wirth \& Schultheiss 2007) and women alone (Cashdan 1995, Grant \& France 2001, Hermans et al. 2006a).

However, as noted by O'Carroll (O'Carroll 1998), the interpretation of these 
results is complicated by the interesting, and better established, observation that men's testosterone levels also fall in response to failures in dominance contests of various kinds (Archer 2006, Dabbs \& Dabbs 2000, Elias 1981, Mazur \& Booth 1998), especially for men who strive more for dominance (Schultheiss et al. 2005). Archer (2006) proposed that this response is part of a primitive, evolved system by which men's willingness to enter dominance contests is informed by their previous record of success. Recent evidence suggests that willingness to enter new contests is influenced by basal testosterone level (Mehta et al. 2008) and/or testosterone response to winning or losing (Carré \& McCormick 2008), and the effect is probably mediated by subtle physiological, rather than psychological, shifts (van Honk et al. 2004). Of course, hormones also have many other nonpsychological functions, including the regulation of muscle mass, which could be evolutionarily meaningful (Bribiescas 2001).

In keeping with the view that male parental investment increased during human evolution, a number of studies have identified possible suppressive effects of romantic relationships, marriage, or fatherhood on testosterone levels in men from several societies and, surprisingly, lesbians (Gray 2003; Gray et al. 2002, 2004, 2006, 2007; Mazur \& Michalek 1998; McIntyre et al. 2006; van Anders \& Watson 2006, 2007). Many of these studies have revealed interesting interactions suggesting that social and psychological factors might play subtle roles in regulating the suppression of testosterone and mating effort.

In the case of coalitional aggression, little evidence indicates that hormones play a major role in sex differences. Burnham (2007) found that men with higher testosterone reject low offers in an economic experiment called the ultimatum game. This could be interpreted simply as a reaction to a perceived threat to personal status or dominance. However, he also noted a nonsignificant trend for men with higher testosterone to make larger offers in the game. Together these trends might suggest a role for testosterone in the establishment of reciprocal relationships through moralistic aggression. However, as we noted, social dominance orientation is the most established measure of group-level affiliation and a recent study found no association of social dominance orientation with either testosterone or 2D:4D (Johnson et al. 2006, McIntyre et al. 2007).

There are a number of established sex differences in the performance of Western adults on a number of cognitive tests, including mental rotation of shapes on which men perform better and verbal and object memory on which women perform better (Kimura 1999). However, Ecuyer-Dab \& Robert (2004) have noted that there are two competing evolutionary interpretations of these differences. They may be part of the primitive systems supporting sex differences in ranging and mate seeking (Gaulin \& FitzGerald 1986, Jones et al. 2003), or they may be derived specifically to support hunting by men and gathering by women (Silverman \& Eals 1992). A sex difference in throwing and targeting ability might be more recently derived in response to male hunting (Westergaard et al. 2000), but the developmental trajectory of these abilities is obviously complex and includes factors such as size and strength, which are often ignored (Jones \& Marlowe 2002). Some of the effects of androgens on mental rotation tasks may not be related to cognitive ability (Hooven et al. 2004), and these associations vary across cultures (Yang et al. 2007).

Given the limitations of evidence coming from adult sex differences, it is useful to consider the role of biological factors in the earlier development of sex differences in infancy and childhood. Researchers with both biological and sociocultural perspectives have turned to studies of children to reduce the complex problem of personal life histories, which result from the continuous transaction of physical, familial, and sociocultural processes with the developing individual. However, we would take this a step further and argue that a better understanding of biosocial interactions over the life course also provides valuable insights into how biological systems affect sex differences, allowing for the formulation of hypotheses 
about how sex differences might develop in a variety of sociocultural systems, including ones that no longer exist (and ones that might someday exist).

\section{The Developmental Course of Gender}

Edwards (1993) noted several differences between the activities of boys and girls observed in many human societies:

1. From age three, girls spend more time working, whereas boys spend more time in play.

2. When playing in groups, children self-segregate by sex, in addition to age.

3. Boys begin to spend more time than girls away from home and their mothers.

4. Girls engage in more infant contact and care.

5. Boys engage in more rough-and-tumble play than girls do.

6. Boys engage in more practice play with weapons and vehicles than girls do.

7. Girls engage in more grooming (real and play) than boys do.

Some cases, such as patterns of rough-andtumble play in boys, the tendency for play groups to segregate by sex, and the high frequency of infant care by girls, demonstrate apparent similarities to patterns observed in other primates (Fagan 1993, Fairbanks 1993).

Sex-different patterns of behavior begin to emerge clearly in young children, during a period when biological sex differentiation is minimal, long before puberty and the development of important secondary sex differences. Patterns of sex segregation, in which children play in same-sex groups, which accompany differences in the types of games played, emerge by five years old and often earlier in many societies (Munroe \& Romney 2006; Whiting \& Edwards 1973, 1988). The psychologist Eleanor Maccoby $(1998,2002)$ has argued that this pattern of sex segregation plays a key role in the development of adult gender. Unfortunately the causes of sex segregation remain poorly understood because most of the proposals have found limited support (Maccoby et al. 1984).

Adults play only a small role in directly encouraging sex segregation in Western societies (Aydt \& Corsaro 2003, Maccoby 1998, Thorne 1993), and their role appears to be even more limited in many other societies in which children are under less supervision (Edwards 1993, 2000; Whiting \& Edwards 1973, 1988). Even when adults try to encourage cross-sex play groups, children resist and quickly return to same-sex partners when adult supervision is reduced (Serbin et al. 1977). These findings are generally supported by twin studies of the heritability of individual variation in gender-related behaviors. Heritability studies allocate variation among three categories (genetic, shared environmental, and nonshared or other environmental variation) based on differential similarities between identical twins, fraternal twins, and other siblings. The role of socialization by parents should mostly appear as shared environmental. Studies of variation in adult and adolescent gender role (as with most other personality dimensions) find moderate genetic effects $(25 \%-50 \%)$ and large nonshared environmental effects $(30 \%-75 \%)$ with little room for substantial effects of family-based socialization (Cleveland et al. 2001, Loehlin et al. 2005). Although recent studies in young children have found larger shared environmental effects, especially in boys (Iervolino et al. 2005, Knafo et al. 2005), this difference might be explained by their use of parent reports about their children's gendered behavior. Rather than finding variation in gender-related behavior attributable to parental influence, they may have found variation in parental attitudes toward their children's gender (a type of rater bias). This is especially likely because effects were stronger in boys, and American parents are more concerned, and have stronger views, about their sons' than their daughters' gender-appropriate behavior (Fagot 1977, Langlois \& Downs 1980).

Older children clearly use cognitive ideas about gender (some of which may come 
from cultural norms) in their play; much of the current thinking about sex segregation focuses on the importance of gender-related sociolinguistic categories to children (Bandura \& Bussey 2004, Kyratzis 2004, Martin \& Ruble 2004) and argues that children choose playmates on the basis of their categorical understanding of their own gender and that of other children (Powlishta et al. 1993, Serbin et al. 2001). These arguments follow Kohlberg's (1966) ideas about the importance of cognitive knowledge about gender, such as knowledge of its constancy. For example, Martin \& Ruble (2004) regard children as young as four years old as "gender detectives" who are actively trying to discover exaggerated stereotypes about men and women by listening to and observing adults and often make amusing errors. Children are motivated first by the knowledge that they are boys or girls and that this will not change (gender constancy) and second by a desire for in-group dominance. This knowledge would imply a fascinating and very radical evolutionary change in which sex differences in adult behaviors, like empathetic parenting by women and dominance striving by men, which appear similar to sex differences observed in many other species, nevertheless develop in a completely novel way via cultural and cognitive processes with limited input from the reproductive endocrine system.

However, there has been some disagreement about whether cognitive knowledge about gender is necessary, especially in younger children. Differences among children in their cognitive understanding of gender are unrelated to the sex of their play partners (Munroe \& Romney 2006, Serbin et al. 1994). Munroe \& Romney (2006) further argue that the term sex aggregation should be used instead of segregation because larger groups of boys, which may or may not include a few girls, break out to engage in rough-and-tumble play. Children who do not join these groups (mostly girls) tend to play alone, in dyads, or in smaller groups. This occurrence implies a primary role for differences between boys and girls in the types of games played rather than in the pre- ferred sex of the play partners. Nevertheless, the limited evidence that exists (all from Western children) about the relationship between play-type preferences and sex-of-partner preferences has been mixed (Alexander \& Hines 1994, Hoffmann \& Powlishta 2001, Moller \& Serbin 1996).

To the extent that segregation or "borderwork," as described by Barrie Thorne, is actively undertaken, scholars have debated its importance and source. Thorne has documented the importance of borderwork in American preschools, and girls seem to play a more important role than boys do. That is, spaces are more likely to be declared off-limits to boys than off-limits to girls (Aydt \& Corsaro 2003, Thorne 1993). This observation also makes sense from Munroe \& Romney's aggregation perspective if sex segregation is being driven partly by refusal on the part of some girls to participate in large-group, rough-and-tumble play.

\section{The Role of Biological Sex Differences}

Secondary sex differentiation in mammals, which has usually been conceived as including behavior, is guided primarily by sex hormones produced in the fetal gonads, especially androgens, and sex differentiation in humans (Hughes 2001) and other primates (Wallen 2005) is thought to entail similar processes. As such, human researchers employing a biological approach to studying behavioral gender in children have focused primarily on prenatal androgens (CohenBendahan et al. 2005, McIntyre \& Hooven 2009). The evidence that childhood sex differences are directly shaped by effects of sex hormones on the brain remains somewhat weak, despite substantial research, but, to be fair, also in the face of substantial methodological limitations (McIntyre \& Hooven 2009). In particular, it is difficult, for technical and ethical reasons, to directly measure prenatal hormones of fetuses in carefully designed studies. However, the possibility that sex segregation is driven partly by sex differences in play preferences provides an opportunity for biological sex differences to influ- 
ence gender development in subtler ways. The construct of temperament (Kagan 2003, Rothbart 1989) might be one avenue for biological influences.

Infant boys and girls show small but consistent differences in dimensions of temperament. In particular, girls show higher fear when confronted with a novel stimulus, expressed as shorter latency to or threshold of crying (Else-Quest et al. 2006, Martin et al. 1997). Boys show a higher motor activity level (Campbell \& Eaton 1999, Else-Quest et al. 2006). Some evidence indicates that individual (and perhaps sex) differences in reactive fear (DiPietro et al. 2008) and especially motor activity (Almli et al. 2001, Eaton \& Saudino 1992, Groome et al. 1999) begin to develop in utero. Infant boys also show greater attention to mechanical crib mobiles than girls do (Connellan et al. 2000), but girls show greater attention to faces by 12 months old (Lutchmaya \& Baron-Cohen 2002). These attentional biases have been linked with toy preferences and characterized as a primitive masculine attentional bias to movement and feminine attentional bias to people (Alexander 2003).

Infant temperament has been further linked with measures of personality later in life that are salient to the dominance/empathy paradigm. Infants with greater fear reactivity develop both greater empathy and social anxiety as toddlers (Spinrad \& Stifter 2006). Although infant temperament has not been studied in relation to later dominance orientation per se in humans, male rhesus monkey infants with higher activity levels rise higher in dominance hierarchies later in life (Weinstein \& Capitanio 2008), and human infants displaying lower fear reactivity (Burgess et al. 2003) and physical activity levels (Canals et al. 2006) display more externalizing behavior as children.

Increasing evidence shows that variation in infant and childhood temperament is influenced by genetic and hormonal factors. Greater attention to faces has been associated with lower prenatal testosterone concentrations measured in amniotic fluid (Lutchmaya et al. 2002). Girls with congenital adrenal hyperplasia show a preference for male-typed toys such as trucks (Meyer-Bahlburg et al. 2004, Pasterski et al. 2005).

These temperamental differences or differences in their effects on later gender development might also result, at least in part, from differential parental treatment of infant boys and girls. However, evidence to date about differential treatment of infant boys and girls has come largely from Western societies and yielded mixed results. The body of findings does not present a strong case for the effect of infant sex or gender label per se on parental treatment, particularly in younger infants (Biringen et al. 1999, Jacklin et al. 1984, Lytton \& Romney 1991, Robinson et al. 1993, Stern \& Karraker 1989). In American infants, individual variations in infant temperament are also almost entirely explicable by genetic variation (Goldsmith et al. 1999), and the presence of analogous sex differences in nonhuman primates (Alexander \& Hines 2002, Hassett et al. 2008, Herman et al. 2003) probably argues against a major role of socialization. Many findings of caregiving variations in treatment of girl and boy infants do not remove variance contributed by what the infants themselves elicit on the basis of their activity levels, capacity for mutual gaze, emotional expressiveness, or other temperamental differences. When child characteristics are included, gender differences in maternal behavior are reduced. For instance, Moss (1967) found that mothers of three-weekold infants were observed to hold, look at, arouse, and stimulate physically sons more than daughters; however, sons were more irritable and when infant irritability was covaried in the analyses differences in holding and looking dropped out. Some researchers (e.g., Donovan et al. 2007) have attempted to remove child-temperament effects by developing experiments in which adults respond to a stranger infant (or photographs), but these studies have the weakness of measuring parental behavior in a nonnatural situation in which they are struggling to read the (often ambiguous) signals of an unknown child and, hence, are in a situation in which they would be expected to be most guided by expectations and stereotypes rather than 
by meaningful child cues. In sum, although it is widely assumed that adult perceptual sets and gender stereotypes influence caregiver behavior toward male versus female infants, independent of the child's characteristics, such differences have not been clearly demonstrated. The issue is complicated even further by the fact that infant girls and boys might react differently to the same caregiver behaviors in light of their own individual differences, such as differences in temperament. For example, boys tend to react more strongly than girls do to differential maternal sensitivity (Biringen et al. 1999, Warren \& Simmens 2005, Weinberg et al. 2006), particularly if the infant is difficult (Warren \& Simmens 2005) or in challenging social contexts (Weinberg et al. 2006). This pattern of transactions between mother and infant could lead to complex amplification of initially small differences in either infant or caregiver behavioral variation, which might also be influenced by the social context, for example, by the extent to which fathers and siblings are involved in care of the child. Bornstein et al. (2008) found that mothers from metropolitan regions were more emotionally available than were those from rural regions, and sons, but not daughters, from metropolitan regions were more responsive than were those from rural regions. These findings suggest that key developmental systems are highly sensitive to sociocultural and/or economic factors, which as Beatrice Whiting (1976) suggested are complex "packaged variables" that need to be broken down and analyzed in terms of components that really matter. Developmental studies about how biological sex differences in children operate in varied social contexts will continue to be informative, particularly as societies are radically transformed by globalization.

\section{Refocusing Biological Studies of Human Gender}

We suggest that biological studies of gender can be benefited by paying more attention to $(a)$ infancy and childhood and $(b)$ broader social processes. Ours is certainly not the first call for complex descriptions of biocultural interactions (Edwards 1993; McIntyre \& Hooven 2009; Worthman 1993, 1995). Biocultural interactions happen repeatedly over the course of life to subjects that are themselves the products of previous interactions. Therefore, we should not be tempted to think that even the bodies of infants are, so to speak, all biology and no culture. Paying attention to broader social processes is a more difficult proposition and will force evolutionary anthropologists and psychologists to gently set aside the reconstructed Paleolithic society in favor of the actual societies in which they work.

For example, some research has shifted greater focus to the individual interests and agency of the child, and adult, actors involved in the day-to-day enactment of gender (Aydt \& Corsaro 2003, Knobloch et al. 2005, Kyratzis 2004). Recent analyses particularly from humanistic (Montgomery 2005), but also from biological (Crittenden \& Marlowe 2008, Hrdy 2005), frameworks have argued for greater attention to the economic value of girls' labor and the roles of parental power and coercion in the establishment of gendered patterns of play and work. This approach might allow us to think about the effects of infant temperament in different ways. The temperaments of young girls, which are characterized by greater empathy, social anxiety, and social attention, might be considered more suitable for doing work around the house and caring for siblings, or they might be more cooperative with mothers owing to their greater physiological maturity and/or same-sex identification (Whiting \& Edwards 1988). Boys, however, might gain agency by virtue of their high levels of physical activity and perceived irresponsibility, freeing them from some household responsibilities.

Similarly interesting questions arise with regard to social institutions outside of the home. Whereas evolutionary anthropologists and psychologists have been looking for associations between testosterone and dominance striving, McIntyre \& Hooven (2009) argue that the reality in Western societies is far more complex and fascinating. Boys with 
high testosterone are dominant over their peers in adolescence (Tremblay et al. 1998), but as they leave the world of peers and family and come into contact with other social institutions the trajectories of their lives are more often characterized by delinquency (Rowe et al. 2004), criminal activities (Archer 2006, Archer et al. 1998), lack of education (Dabbs \& Dabbs 2000), and low social prestige (Dabbs 1992, Johnson et al. 2007). Even if this tendency results from a mismatch between ancestral and current conditions, it is a mismatch worthy of careful study, if for no other reason than it is likely to affect the results of any research that we conduct. It is not possible to escape these questions by studying simpler societies.

Our suggestions are similar to those of Goodman \& Leatherman's (1998) Biocultural Synthesis, which encourages more study of the effects of political and economic systems on human biology but applied to reproductive biology and sex differences, in addition to nutrition and growth. We also echo some of Bourdieu's observations about patriarchy. "The biological appearances and the very real effects which have been produced, in people's bodies and in their brains, by a long collective labor of socialization of the biological and of biologization of the social combine to overturn the relationship between causes and effects..." (Bourdieu 1990, p. 12). We further argue that biological work relying on insights from humanistic social science research, far from being an alternative to evolutionary explanations (Bribiescas 2001, Ellison 2003), can also make the social sciences more useful contributors to biological and evolutionary thinking about gender in other species. Recent work in a number of species, including those whose biological gender can reverse during life, has highlighted the central roles of social stratification, power differences, and coercive or violent tactics in explaining patterns of sex or gender role change (Anthes \& Michiels 2007, Black \& Grober 2003, Grober \& Rodgers 2008, Rodgers et al. 2007). As these processes are particularly elaborated and varied in humans, the human sciences might offer rich and surprising theoretical insights, even for ichthyologists.

\section{Summary Points}

1. For the most part, biological influences on psychological sex differences probably occur early in life via simple mechanisms such as temperament.

2. Small sex differences in temperament interact with social factors in complex ways that might result in further psychological differentiation but not always in ways that are clearly predicted by existing evolutionary theories.

\section{Future Issues}

1. How do sex differences in physical maturity and social competence influence how children interact with one another or are treated by adults, and what are the biological or social causes of these sex differences?

2. More evidence is needed about the social processes and individual differences that result in sex segregation in children. In particular, the relative importance of gender cognitions and activity or play-style preferences remains unclear.

3. Longer-term longitudinal studies would help us to understand the role of early processes (including sex segregation) on the further consolidation of psychological sex differences during puberty and adulthood.

\section{Literature Cited}

Alexander GM. 2003. An evolutionary perspective of sex-typed toy preferences: pink, blue, and the brain. Arch. Sex. Behav. 32:7-14

Alexander GM, Hines M. 1994. Gender labels and play styles - their relative contribution to children's selection of playmates. Child Dev. 65:869-79

Alexander GM, Hines M. 2002. Sex differences in response to children's toys in nonhuman primates (Cercopithecus aethiops sabaeus). Evol. Hum. Behav. 23:467-79

Almli CR, Ball RH, Wheeler ME. 2001. Human fetal and neonatal movement patterns: gen- 
der differences and fetal-to-neonatal continuity. Dev. Psychobiol. 38:252-73

Anthes N, Michiels NK. 2007. Precopulatory stabbing, hypodermic injections and unilateral copulations in a hermaphroditic sea slug. Biol. Lett. 3:121-24

Archer J. 2006. Testosterone and human aggression: an evaluation of the challenge hypothesis. Neurosci. Biobehav. Rev. 30:319-45

Archer J, Birring SS, Wu FCW. 1998. The association between testosterone and aggression among young men: empirical findings and a meta-analysis. Aggressive Behav. 24:411-20

Aydt H, Corsaro WA. 2003. Differences in children's construction of gender across culture-an interpretive approach. Am. Behav. Sci. 46:1306-25

Bandura A, Bussey K. 2004. On broadening the cognitive, motivational, and sociostructural scope of theorizing about gender development and functioning: comment on Martin, Ruble, and Szkrvbalo (2002). Psychol. Bull. 130:691-701

Baron-Cohen S. 2002. The extreme male brain theory of autism. Trends Cognit. Sci. 6:248-54

Bateman AJ. 1948. Intrasexual selection on Drosophila. Heredity 2:349-68

Biringen Z, Emde RN, Brown D, Lowe L, Myers S, Nelson D. 1999. Emotional availability and emotion communication in naturalistic mother-infant interactions: evidence for gender relations. J. Soc. Person. Relat. 14:463-78

Black MP, Grober MS. 2003. Group sex, sex change, and parasitic males: sexual strategies among the fishes and their neurobiological correlates. Annu. Rev. Sex. Res. 14:160-84

Bornstein MH, Putnick DL, Heslington M, Gini M, Suwalsky JTD, et al. 2008. Mother-child emotional availability in ecological perspective: three countries, two regions, two genders. Dev. Psychol. 44:666-80

Bourdieu P. 1990. La domination masculine. Actes Rech. Sci. Soc. 84:3-31

Bribiescas RG. 2001. Reproductive ecology and life history of the human male. Am. J. Phys. Anthropol. 33(Suppl.):148-76
Burgess KB, Marshall PJ, Rubin KH, Fox NA. 2003. Infant attachment and temperament as predictors of subsequent externalizing problems and cardiac physiology. J. Child. Psychol. Psychiatry 44:819-31

Burgoon JK, Johnson ML, Koch PT. 1998. The nature and measurement of interpersonal dominance. Commun. Monogr. 65:308-35

Burnham TC. 2007. High-testosterone men reject low ultimatum game offers. Proc. R. Soc. London Ser. B Biol. Sci. 274:2327-30

Campbell A. 2006. Sex differences in direct aggression: What are the psychological mediators? Aggr. Violent Behav. 11:237-64

Campbell DW, Eaton WO. 1999. Sex differences in the activity level of infants. Infant Child Dev. 8:1-17

Canals J, Esparo G, Fernandez-Ballart JD. 2006. Neonatal behavior characteristics and psychological problems at 6 years. Acta Paediatr. 95:1412-17

Carré JM, McCormick CM. 2008. Aggressive behavior and change in salivary testosterone concentrations predict willingness to engage in a competitive task. Horm. Behav. 54:403-9

Cashdan E. 1995. Hormones, sex, and status in women. Horm. Behav. 29:354-66

Cleveland HH, Udry JR, Chantala K. 2001. Environmental and genetic influences on sextyped behaviors and attitudes of male and female adolescents. Person. Soc. Psychol. Bull. 27:1587-98

Clutton-Brock TH. 1989. Mammalian mating systems. Proc. R. Soc. London Ser. B Biol. Sci. 236:339-72

Clutton-Brock TH, Parker GA. 1992. Potential reproductive rates and the operation of sexual selection. Q. Rev. Biol. 67:437-56

Cohen-Bendahan CCC, van de Beek C, Berenbaum SA. 2005. Prenatal sex hormone effects on child and adult sex-typed behavior: methods and findings. Neurosci. Biobehav. Rev. 29:353-84

Connellan J, Baron-Cohen S, Wheelwright S, Batki A, Ahluwalia J. 2000. Sex differences in human neonatal social perception. Infant Behav. Dev. 23:113-18

Crittenden AN, Marlowe FW. 2008. Allomaternal care among the Hadza of Tanzania. Hum. Nat.-Interdiscip. Biosoc. Perspect. 19:249-62 
Dabbs JM. 1992. Testosterone and occupational achievement. Soc. Forces 70:813-24

Dabbs JM. 1997. Testosterone, smiling, and facial appearance. J. Nonverbal Behav. 21:45-55

Dabbs JM, Dabbs MG. 2000. Heroes, Rogues, and Lovers: Testosterone and Behavior. New York: McGraw-Hill

Deady DK, Law-Smith MJ, Sharp MA, Al-Dujaili EAS. 2006. Maternal personality and reproductive ambition in women is associated with salivary testosterone levels. Biol. Psychol. 71:29-32

Dewsbury DA. 1982. Dominance rank, copulatory behavior, and differential reproduction. Q. Rev. Biol. 57:135-59

DiPietro JA, Ghera MM, Costigan KA. 2008. Prenatal origins of temperamental reactivity in early infancy. Early Hum. Dev. 84:569-75

Donovan W, Taylor N, Leavitt L. 2007. Maternal sensory sensitivity and response bias in detecting change in infant facial expressions: maternal self-efficacy and infant gender labeling. Infant Behav. Dev. 30:436-52

Eaton WO, Saudino KJ. 1992. Prenatal activity level as a temperament dimension-individual differences and developmental functions in fetal movement. Infant Behav. Dev. 15:57-70

Ecuyer-Dab I, Robert M. 2004. Have sex differences in spatial ability evolved from male competition for mating and female concern for survival? Cognition 91:221-57

Edwards CP. 1993. Behavioral sex differences in children of diverse cultures: the case of nurturance to infants. See Pereira \& Fairbanks 1993, pp. 327-38

Edwards CP. 2000. Children's play in cross-cultural perspective: a new look at the six cultures study. Cross Cult. Res. 34:318-38

Elias M. 1981. Serum cortisol, testosterone, and testosterone-binding globulin responses to competitive fighting in human males. Aggress. Behav. 7:215-24

Ellison PT. 2003. Energetics and reproductive effort. Am. J. Hum. Biol. 15:342-51

Else-Quest NM, Hyde JS, Goldsmith HH, Van Hulle CA. 2006. Gender differences in temperament: a meta-analysis. Psychol. Bull. 132:33-72
Fagan R. 1993. Primate juveniles and primate play. See Pereira \& Fairbanks 1993, pp. 182-96

Fagot BI. 1977. Consequences of moderate crossgender behavior in preschool children. Child Dev. 48:902-7

Fairbanks LA. 1993. Juvenile vervet monkeys: establishing relationships and practicing skills for the future. See Pereira \& Fairbanks 1993, pp. 212-27

Fuentes A. 1998. Re-evaluating primate monogamy. Am. Anthropol. 100:890-907

Gaulin SJC, FitzGerald RW. 1986. Sex differences in spatial ability: an evolutionary hypothesis and test. Am. Nat. 127:74-88

Geary DC. 2002. Sexual selection and human life history. Adv. Child Dev. Behav. 30:41-101

Geary DC. 2006. Sex differences in social behavior and cognition: utility of sexual selection for hypothesis generation. Horm. Behav. 49:273-75

Goldsmith HH, Lemery KS, Buss KA, Campos JJ. 1999. Genetic analyses of focal aspects of infant temperament. Dev. Psychol. 35:972-85

Goodman A, Leatherman T. 1998. Building a New Biocultural Synthesis: Political-Economic Perspectives on Human Biology. Ann Arbor: Univ. Mich. Press

Grant VJ, France JT. 2001. Dominance and testosterone in women. Biol. Psychiatry 58:41-47

Gray PB. 2003. Marriage, parenting, and testosterone variation among Kenyan Swahili men. Am. J. Phys. Anthropol. 122:279-86

Gray PB, Chapman JF, Burnham TC, McIntyre MH, Lipson SF, Ellison PT. 2004. Human male pair bonding and testosterone. Hum. Nat. Interdiscip. Biosoc. Perspect. 15:119-31

Gray PB, Ellison PT, Campbell BC. 2007. Testosterone and marriage among Ariaal men of Northern Kenya. Curr. Anthropol. 48:750-55

Gray PB, Kahlenberg SM, Barrett ES, Lipson SF, Ellison PT. 2002. Marriage and fatherhood are associated with lower testosterone in males. Evol. Hum. Behav. 23:193-201

Gray PB, Yang CFJ, Pope HG. 2006. Fathers have lower salivary testosterone levels than unmarried men and married nonfathers in Beijing, China. Proc. R. Soc. London Ser. B Biol. Sci. 273:333-39 
Grober MS, Rodgers EW. 2008. The evolution of hermaphroditism. J. Theor. Biol. 251:190-92

Groome LJ, Swiber MJ, Holland SB, Bentz LS, Atterbury JL, Trimm RF. 1999. Spontaneous motor activity in the perinatal infant before and after birth: stability in individual differences. Dev. Psychobiol. 35:15-24

Hassett JM, Siebert ER, Wallen K. 2008. Sex differences in rhesus monkey toy preferences parallel those of children. Horm. Behav. 54:359-64

Hawkes K, O'Connell JF, Jones NGB. 1991. Hunting income patterns among the Hadza - big game, common goods, foraging goals and the evolution of the human diet. Philos. Trans. R. Soc. London Ser. B Biol. Sci. 334:243-51

Hawkes K, O'Connell JF, Jones NGB. 2001. Hunting and nuclear families-some lessons from the Hadza about men's work. Curr. Anthropol. 42:681-709

Herman RA, Measday MA, Wallen K. 2003. Sex differences in interest in infants in juvenile rhesus monkeys: relationship to prenatal androgen. Horm. Behav. 43:573-83

Hermans EJ, Putman P, Baas JM, Koppeschaar HP, van Honk J. 2006a. A single administration of testosterone reduces fear-potentiated startle in humans. Biol. Psychiatry 59:872-74

Hermans EJ, Putman P, van Honk J. 2006b. Testosterone administration reduces empathetic behavior: a facial mimicry study. Psychoneuroendocrinology 31:859-66

Hill K, Kaplan H. 1993. On why male foragers hunt and share food. Curr. Anthropol. 34:701-10

Hoffmann ML, Powlishta KK. 2001. Gender segregation in childhood: a test of the interaction style theory. J. Genet. Psychol. 162:298-313

Hooven CK, Chabris CF, Ellison PT, Kosslyn SM. 2004. The relationship of male testosterone to components of mental rotation. Neuropsychologia 42:782-90

Hrdy SB. 2005. Comes the child before the man: how cooperative breeding and prolonged postweaning dependence shaped human potentials. In Hunter-Gatherer Childhoods, ed. BS Hewlett, ME Lamb, pp. 65-91. Piscataway, NJ: Aldine Transaction
Hughes IA. 2001. Minireview: sex differentiation. Endocrinology 142:3281-87

Iervolino AC, Hines M, Golombok SE, Rust J, Plomin R. 2005. Genetic and environmental influences on sex-typed behavior during the preschool years. Child Dev. 76:826-40

Jacklin CN, Dipietro JA, Maccoby EE. 1984. Sextyping behavior and sex-typing pressure in child parent interaction. Arch. Sex. Behav. 13:413-25

Jarman P. 1983. Mating system and sexual dimorphism in large, terrestrial, mammalian herbivores. Biol. Rev. Camb. Philos. Soc. 58:485-520

Johnson DDP, McDermott R, Barrett ES, Cowden J, Wrangham R, et al. 2006. Overconfidence in wargames: experimental evidence on expectations, aggression, gender and testosterone. R. Soc. London Ser. B Biol. Sci. 273:2513-20

Johnson RT, Burk JA, Kirkpatrick LA. 2007. Dominance and prestige as differential predictors of aggression and testosterone levels in men. Evol. Hum. Behav. 28:345-51

Jones CM, Braithwaite VA, Healy SD. 2003. The evolution of sex differences in spatial ability. Behav. Neurosci. 117:403-11

Jones NB, Marlowe FW. 2002. Selection for delayed maturity-Does it take 20 years to learn to hunt and gather? Hum. Nat.-Interdiscip. Biosoc. Perspect. 13:199-238

Kagan J. 2003. Biology, context, and developmental inquiry. Annu. Rev. Psychol. 54:1-23

Kaplan H, Hill K, Lancaster J, Hurtado AM. 2000. A theory of human life history evolution: diet, intelligence, and longevity. Evol. Anthropol. 9:156-85

Kimura D. 1999. Sex and Cognition. Cambridge, MA: MIT Press

Knafo A, Iervolino AC, Plomin R. 2005. Masculine girls and feminine boys: genetic and environmental contributions to atypical gender development in early childhood. $J$. Person. Soc. Psychol. 88:400-12

Knobloch S, Callison C, Chen L, Fritzsche A, Zillmann D. 2005. Children's sex-stereotyped self-socialization through selective exposure to entertainment: cross-cultural experiments in Germany, China, and the United States. J. Commun. 55:122-38 
Kohlberg L. 1966. A cognitive-developmental analysis of children's sex role concepts and attitudes. In The Development of Sex Differences, ed. EE Maccoby, pp. 82-173. Stanford, CA: Stanford Univ. Press

Kokko H, Jennions MD, Brooks R. 2006. Unifying and testing models of sexual selection. Annu. Rev. Ecol. Evol. Syst. 37:43-66

Kyratzis A. 2004. Talk and interaction among children and the coconstruction of peer groups and peer culture. Annu. Rev. Anthropol. 33:625-49

Langlois JH, Downs AC. 1980. Mothers, fathers, and peers as socialization agents of sex-typed play behaviors in young children. Child Dev. 51:1237-47

Loehlin JC, Jonsson EG, Gustavsson JP, Stallings MC, Gillespie NA, et al. 2005. Psychological masculinity-femininity via the gender diagnosticity approach: heritability and consistency across ages and populations. J. Person. 73:1295-319

Lutchmaya S, Baron-Cohen S. 2002. Human sex differences in social and nonsocial looking preferences, at 12 months of age. Infant Behav. Dev. 25:319-25

Lutchmaya S, Baron-Cohen S, Raggatt P. 2002. Fetal testosterone and eye contact in 12month-old human infants. Infant Behav. Dev. 25:327-35

Lytton H, Romney DM. 1991. Parents' differential socialization of boys and girls: a metaanalysis. Psychol. Bull. 109:267-96

Maccoby EE. 1998. The Two Sexes: Growing Up Apart, Coming Together. Cambridge, MA: Harvard Univ. Press

Maccoby EE. 2002. Gender and group process: a developmental perspective. Curr. Dir. Psychol. Sci. 11:54-58

Maccoby EE, Snow ME, Jacklin CN. 1984. Childrens dispositions and mother child interaction at 12 and 18 months - a short-term longitudinal-study. Dev. Psychol. 20:459-72

Martin CL, Ruble D. 2004. Children's search for gender cues-cognitive perspectives on gender development. Curr. Dir. Psychol. Sci. 13:67-70

Martin RP, Wisenbaker J, Baker J, Huttunen MO. 1997. Gender differences in temperament at six months and five years. Infant Behav. Dev. 20:339-47
Mazur A, Booth A. 1998. Testosterone and dominance in men. Behav. Brain Sci. 21:353-97

Mazur A, Michalek J. 1998. Marriage, divorce, and male testosterone. Soc. Forces 77:315-30

McIntyre MH. 2006. The use of digit ratios as markers for perinatal androgen action. Reprod. Biol. Endocrinol. 2:10

McIntyre MH, Barrett ES, McDermott R, Johnson DDP, Cowden J, Rosen SP. 2007. Finger length ratio (2D:4D) and sex differences in aggression during a simulated war game. Person. Ind. Diff. 42:755-64

McIntyre MH, Gangestad SW, Gray PB, Chapman JF, Burnham TC, et al. 2006. Romantic involvement often reduces men's testosterone levels - but not always: the moderating role of extrapair sexual interest. J. Person. Soc. Psychol. 91:642-51

McIntyre MH, Hooven CK. 2009. Human sex differences in social relationships: organizational and activational effects of androgens. In Endocrinology of Social Relationships, ed. PB Gray, PT Ellison, pp. 225-45. Cambridge, MA: Harvard Univ. Press

Mehta PH, Jones AC, Josephs RA. 2008. The social endocrinology of dominance: basal testosterone predicts cortisol changes and behavior following victory and defeat. J. Person. Soc. Psychol. 94:1078-93

Meyer-Bahlburg HFL, Dolezal C, Baker SW, Carlson AD, Obeid JS, New MI. 2004. Prenatal androgenization affects gender-related behavior but not gender identity in 5-12year-old girls with congenital adrenal hyperplasia. Arch. Sex. Behav. 33:97-104

Moller LC, Serbin LA. 1996. Antecedents of toddler gender segregation: cognitive consonance, gender-typed toy preferences and behavioral compatibility. Sex Roles 35:445-60

Montgomery H. 2005. Gendered childhoods: a cross disciplinary overview. Gend. Educ. 17:471-82

Moss HA. 1967. Sex, age, and state as determinants of mother-infant interaction. Merrill Palmer Q. J. Dev. Psychol. 13:19-36

Munroe RL, Romney AK. 2006. Gender and age differences in same-sex aggregation and social behavior - a four-culture study. J. Cross Cult. Psychol. 37:3-19 
O'Carroll RE. 1998. Placebo-controlled manipulations of testosterone levels and dominance. Behav. Brain Sci. 21:382-83

Orians GH. 1969. On evolution of mating systems in birds and mammals. Am. Nat. 103:589-603

Pasterski VL, Geffner ME, Brain C, Hindmarsh P, Brook C, Hines M. 2005. Prenatal hormones and postnatal socialization by parents as determinants of male-typical toy play in girls with congenital adrenal hyperplasia. Child Dev. 76:264-78

Pereira ME, Fairbanks LA, eds. 1993. Juvenile Primates: Life History, Development, and Behavior. New York/Oxford: Oxford Univ. Press

Plavcan JM. 2001. Sexual dimorphism in primate evolution. Yearb. Phys. Anthropol. 44:25-53

Powlishta KK, Serbin LA, Moller LC. 1993. The stability of individual differences in gender typing-implications for understanding gender segregation. Sex Roles 29:723-37

Pratto F, Sidanius J, Stallworth LM, Malle BF. 1994. Social-dominance orientation - a personality variable predicting social and political attitudes. J. Person. Soc. Psychol. 67:741-63

Robinson J, Little C, Biringen Z. 1993. Emotional communication in mother-toddler relationships-evidence for early gender differentiation. Merrill Palmer Q. J. Dev. Psychol. 39:496-517

Rodgers EW, Earley RL, Grober MS. 2007. Social status determines sexual phenotype in the bi-directional sex changing bluebanded goby Lythrypnus dalli. J. Fish Biol. 70:1660-68

Rothbart MK. 1989. Temperament in childhood: a framework. In Temperament in Childhood, ed. JE Kohnstamn, JE Bates, MK Rothbart, pp. 59-73. New York: Wiley

Rowe R, Maughan B, Worthman CM, Costello EJ, Angold A. 2004. Testosterone, antisocial behavior, and social dominance in boys: pubertal development and biosocial interaction. Biol. Psychiatry 55:546-52

Schultheiss OC, Wirth MM, Torges CM, Pang JS, Villacorta MA, Welsh KM. 2005. Effects of implicit power motivation on men's and women's implicit learning and testosterone changes after social victory or defeat. J. Person. Soc. Psychol. 88:174-88
Sellers JG, Mehl MR, Josephs RA. 2007. Hormones and personality: testosterone as a marker of individual differences. J. Res. Pers. 41:126-38

Serbin LA, Moller LC, Gulko J, Powlishta KK, Colburne KA. 1994. The emergence of gender segregation in toddler playgroups. New Dir. Child Dev. 65:7-17

Serbin LA, Poulin-Dubois D, Colburne KA, Sen MG, Eichstedt JA. 2001. Gender stereotyping in infancy: visual preferences for and knowledge of gender-stereotyped toys in the second year. Int. J. Behav. Dev. 25:7-15

Serbin LA, Tonick IJ, Sternglanz SH. 1977. Shaping interaction in same and cross-sex play. Child Dev. 48:924-29

Silverman I, Eals M. 1992. Sex differences in spatial abilites: evolutionary theory and data. In The Adapted Mind: Evolutionary Psychology and the Generation of Culture, ed. $\mathrm{JH}$ Barkow, L Cosmides, J Tooby, pp. 533-49. Oxford, UK: Oxford Univ. Press

Smuts B. 1995. The evolutionary origins of patriarchy. Hum. Nat.-Interdiscip. Biosoc. Perspect. 6:1-32

Spinrad TL, Stifter CA. 2006. Toddlers' empathy-related responding to distress: predictions from negative emotionality and maternal behavior in infancy. Infancy 10:97-121

Stern M, Karraker KH. 1989. Sex stereotyping of infants: a review of gender labeling studies. Sex Roles 20:501-22

Thorne B. 1993. Gender Play: Girls and Boys in School. New Brunswick, NJ: Rutgers Univ. Press

Tremblay RE, Schaal B, Boulerice B, Arseneault L, Soussignan RG, et al. 1998. Testosterone, physical aggression, dominance, and physical development in early adolescence. Int. J. Behav. Dev. 22:753-77

Trivers R. 1972. Parental investment and sexual selection. In Sexual Selection and the Descent of Man, 1871-1971, ed. B Campbell, pp. 13679. Chicago: Aldine

van Anders SM, Watson NV. 2006. Relationship status and testosterone in North American heterosexual and nonheterosexual men and women: cross-sectional and longitudinal data. Psychoneuroendocrinology 31:715-23 
van Anders SM, Watson NV. 2007. Testosterone levels in women and men who are single, in long-distance relationships, or same-city relationships. Horm. Behav. 51:286-91

van Honk J, Schutter D, Hermans EJ, Putman P. 2004. Testosterone, cortisol, dominance, and submission: biologically prepared motivation, no psychological mechanisms involved. Behav. Brain Sci. 27:160-62

Wade MJ, Shuster SM. 2002. The evolution of parental care in the context of sexual selection: a critical reassessment of parental investment theory. Am. Nat. 160:285-92

Wallen K. 2005. Hormonal influences on sexually differentiated behavior in nonhuman primates. Frontiers Neuroendocrinol. 26:7-26

Warren SL, Simmens SJ. 2005. Predicting toddler anxiety/depressive symptoms: effects of caregiver sensitivity on temperamentally vulnerable children. Infant Mental Health J. 26:40-55

Weinberg MK, Olson KL, Beeghly M, Tronick EZ. 2006. Making up is hard to do, especially for mothers with high levels of depressive symptoms and their infant sons. J. Child. Psychol. Psychiatry 47:670-83

Weinstein TAR, Capitanio JP. 2008. Individual differences in infant temperament predict social relationships of yearling rhesus monkeys, Macaca mulatta. Anim. Behav. 76:455-65

Westergaard GC, Liv C, Haynie MK, Suomi SJ. 2000. A comparative study of aimed throw- ing by monkeys and humans. Neuropsychologia 38:1511-17

Whiting BB. 1976. The problem of the packaged variable. In The Developing Individual in a Changing World, Vol. 1: Historical and Cultural Issues, ed. KF Riegel, JA Meacham, pp. 303-9. The Hague: Mouton

Whiting BB, Edwards CP. 1973. A cross cultural analysis of sex differences in the behavior of children aged 3 to 11. J. Soc. Psychol. 91:171-88

Whiting BB, Edwards CP. 1988. Children of Different Worlds: The Formation of Social Behavior. Cambridge, MA: Harvard Univ. Press

Wirth MM, Schultheiss OC. 2007. Basal testosterone moderates responses to anger faces in humans. Physiol. Behav. 90:496-505

Wobst HM. 1978. Archaeo-ethnology of huntergatherers or tyranny of the ethnographic record in archeology. Am. Antiq. 43:303-9

Worthman CM. 1993. Biocultural interactions in human devolopment. See Pereira \& Fairbanks 1993, pp. 339-58

Worthman CM. 1995. Hormones, sex, and gender. Annu. Rev. Anthropol. 24:593-617

Wrangham RW. 1999. Evolution of coalitionary killing. Yeab. Phys. Anthropol. 42:1-30

Yang CFJ, Hooven CK, Boynes M, Gray PB, Pope HG. 2007. Testosterone levels and mental rotation performance in Chinese men. Horm. Behav. 51:373-78 